\title{
The influence of temperature and photoperiod on the timing of brood onset in hibernating honey bee colonies
}

\author{
Fabian Nürnberger ${ }^{\text {Corresp., }}{ }^{1}$, Stephan Härtel ${ }^{1}$, Ingolf Steffan-Dewenter ${ }^{1}$ \\ ${ }^{1}$ Department of Animal Ecology and Tropical Biology, Bayerische Julius-Maximilians-Universität Würzburg, Würzburg, Germany \\ Corresponding Author: Fabian Nürnberger \\ Email address: fabian.nuernberger@uni-wuerzburg.de
}

In order to save resources, honey bee (Apis mellifera) colonies in the temperate zones stop brood rearing during winter. Brood rearing is resumed in late winter to build up a sufficient worker force that allows to exploit floral resources in upcoming spring. The timing of brood onset in hibernating colonies is crucial and a premature brood onset could lead to an early depletion of energy reservoirs. However, the mechanisms underlying the timing of brood onset and potential risks of mistiming in the course of ongoing climate change are not well understood. To assess the relative importance of ambient temperature and photoperiod as potential regulating factors for brood rearing activity in hibernating colonies, we overwintered 24 honey bee colonies within environmental chambers. The colonies were assigned to two different temperature treatments and three different photoperiod treatments to disentangle the individual and interacting effects of temperature and photoperiod. Tracking in-hive temperature as indicator for brood rearing activity revealed that increasing ambient temperature triggered brood onset. Under cold conditions, photoperiod alone did not affect brood onset, but the light regime altered the impact of higher ambient temperature on brood rearing activity. Further the number of brood rearing colonies increased with elapsed time which suggests the involvement of an internal clock. We conclude that timing of brood onset in late winter is mainly driven by temperature but modulated by photoperiod. Climate warming might change the interplay of these factors and result in mismatches of brood phenology and environmental conditions. 
1 Title:

2 The influence of temperature and photoperiod on the timing of brood onset in hibernating

3 honey bee colonies

4

5 Authors:

6

7

8

9

10

11

12

13

14

15

16

17

18

19

20
${ }^{1}$ Department of Animal Ecology and Tropical Biology, Biocenter, University of Würzburg

Würzburg

Germany

*Corresponding author:

Fabian Nürnberger

Department of Animal Ecology and Tropical Biology, Biocenter, University of Würzburg

Am Hubland, 97074 Würzburg, Germany

Email address: fabian.nuernberger@uni-wuerzburg.de 
21 Abstract

22 Honey bee (Apis mellifera) colonies in the temperate zones stop brood rearing during winter to

23 save resources. Brood rearing is resumed in late winter to build up a sufficient worker force that

24 allows the exploitation of floral resources in the upcoming spring. The timing of brood onset in

25 hibernating colonies is crucial as a premature brood onset could lead to an early depletion of

26 energy reservoirs. However, the mechanisms underlying the timing of brood onset and potential

27 risks of mistiming in the course of ongoing climate change are not well understood. This may

28 partially be due to the fact that tracking brood rearing activity in winter is challenging and previously applied methods were highly invasive. To assess the relative importance of ambient temperature and photoperiod as potential regulating factors for brood rearing activity, we hibernated 24 honey bee colonies in environmental chambers. The colonies were assigned to two different temperature treatments and three different photoperiod treatments to disentangle the individual and interacting effects of temperature and photoperiod. By tracking in-hive temperature, we successfully applied a method to detect brood rearing activity within colonies without disrupting the winter cluster. Our experiment revealed that increasing ambient temperature triggered brood onset. Under cold conditions, photoperiod alone did not affect brood onset, but the light regime altered the impact of higher ambient temperature on brood rearing activity. Further the number of brood rearing colonies increased with elapsed time which suggests the involvement of an internal clock. We conclude that timing of brood onset in late winter is mainly driven by temperature but modulated by photoperiod. Climate warming might change the interplay of these factors and result in mismatches of brood phenology and environmental conditions. 


\section{Introduction}

45 The timing of life-history events, such as flowering in plants, insect emergence, and

46 reproduction, with respect to the changing abiotic and biotic conditions of the environment is

47 critical for most organisms (van Asch \& Visser 2007; Visser et al. 2004). In temperate regions,

48 environmental conditions during winter are important drivers of phenology (Williams et al.

492015 ) as organisms need to cope with low temperature conditions and often drastically reduced

resource availability. Most ectotherms hibernate in a state of dormancy at different stages of

51 development. Endothermic mammals generally keep their body temperature actively above ambient temperature, but often go into a state of reduced metabolism, i.e. hibernation or daily torpor, to reduce energy expenditure and tend not to reproduce during winter (Körtner \& Geiser 2000). Due to their capability of social thermoregulation, honey bees (Apis mellifera L.) are able to maintain colonies over the whole year (Jones \& Oldroyd 2006), using a strategy analogous to

56 hibernation in mammals. Much like mammals that undergo hypothermic phases during

57 hibernation, the honey bee colony is effectively heterothermic. When the colony experiences

58 cold stress the workers of a colony tend to remain relatively inactive and cluster up densely in the so-called winter cluster to reduce colony heat loss (Southwick 1985), while individual workers actively produce heat by flight muscle shivering to keep the cluster core temperature above ambient temperature (Esch 1964; Stabentheiner 2005). In brood rearing honey bee colonies, the degree and accuracy of thermoregulation is exceptionally high (Fahrenholz et al.

63 1989; Jones et al. 2004; Kronenberg \& Heller 1982). This is necessary as the larvae of honey

64 bees require a higher and more stable temperature than workers to survive and develop well.

65 Even minor deviations from the optimal temperature-window during development can lead to 66 decreased fitness in adult workers (Jones et al. 2005; Tautz et al. 2003). Thermoregulation is 
67 highly energy demanding (Stabentheiner et al. 2010). To save resources while foraging is not

68 possible, honey bee colonies refrain from large-scale brood rearing during temperate zone winters. Anticipating resource availability in spring, colonies resume brood rearing already in late winter. The timing of brood onset is critical for colony fitness (Seeley \& Visscher 1985). Premature brood onset increases the risk of starvation before spring bloom and can lead to increased loads of the brood parasite Varroa destructor. Late brood onset, on the other hand, decreases the ability to exploit spring bloom. In both ways, wrong timing of brood onset can result in reduced colony growth, colony reproduction, and increased mortality during hibernation. Emergence from hibernation before new resources are available is also seen in several mammal species. Increased risk of predation and starvation are hazarded in order to reproduce early so that the offspring has sufficient time to develop and build up resource storages or fat-tissue before the next winter (Körtner \& Geiser 2000; Meyer et al. 2016).

To date, very little is known on how honey bee colonies achieve an optimal timing of brood onset and which environmental factors are used as predictive cues during winter. Across many taxa increasing ambient temperature and length of photoperiod serve as cues to time phenological events like emergence after hibernation or reproduction (Bradshaw \& Holzapfel 2007; Körtner \& Geiser 2000; Visser 2013). In addition, endogenous circannual clocks can control the timing of hibernation (Körtner \& Geiser 2000). Nothing is known about the role of internal clocks for timing of brood onset in honey bees. But it is generally assumed that ambient temperature does affect brood rearing activity in honey bee colonies in winter and it has been

87 shown that photoperiod can affect brood rearing activity in summer (Kefuss 1978). Empirical evidence for effects of ambient temperature or photoperiod on brood rearing in winter, however, is still lacking. This is probably because tracking the status of brood rearing within the winter 
90 cluster is difficult and generally highly invasive. We argue that a new method to detect brood

91 rearing without disrupting the winter cluster is necessary to increase our understanding of the

92 phenology of brood rearing activity in honey bee colonies. In light of ongoing climate change,

93 well-founded information on the impact of environmental conditions on honey bee phenology is

94 critically needed if we want to assess potential consequences of climate change for one of the

95 most ecologically and economically important pollinators (Potts et al. 2016). Climate change and

96 especially changing winter conditions have already been shown to alter timing of life history-

97 stages in many organisms (Williams et al. 2015) and resulting mismatches with the environment

98 can lead to severe fitness losses in wild bees (Schenk et al. 2018).

99 In this study we demonstrated that tracking the daily temperature variation within the winter

100 cluster allows to draw conclusions on the state of brood rearing in a minimally invasive way. We

101 applied this method to investigate the effects of ambient temperature, photoperiod and elapsed

102 time on the brood rearing status within the winter cluster of honey bee colonies. We expected

103 ambient temperature to have a major effect on timing of brood onset that is modulated by

104 photoperiod and elapsed time.

106 Material and Methods

107 Study organism

108 Twenty-four equally sized colonies of $A$. mellifera carnica (Pollmann, 1879) headed by sister-

109 queens were established in July 2014. Queens were artificially inseminated with 8-10 $\mu 1$ sperm

110 of ten drones all belonging to the same drone population in cooperation with the Institut für

111 Bienenkunde, Oberursel, Frankfurt University. Artificial swarms with $600 \mathrm{~g}$ of workers and a 
112 queen were placed into two-storied miniPlus-hive boxes with 12 empty wax-sheet frames and

113 fed with sugar syrup (Apiinvert, Südzucker) during August to October 2014 to enable comb

114 construction and ensure sufficient honey stores. Colonies were treated against the brood parasite

115 Varroa destructor using Bayvarol ${ }^{\circledR}$-strips (Bayer) for 6 weeks in August and September 2014 as

116 a precaution measure. No visually noticeable signs of common diseases were detected during 2-

117 weekly colony monitoring until September 2014. It was confirmed that all colonies successfully

118 reared worker brood before hibernation and all colonies were adjusted in September 2014 to

119 make sure that they contained approximately the same amounts of workers and honey stores. All

120 colonies were placed into two environmental chambers in December 2014 (12 colonies in each

121 chamber) and kept at $0^{\circ} \mathrm{C}$ daily mean temperature with daily oscillation from $-3^{\circ} \mathrm{C}$ during

122 midnight to $+3^{\circ} \mathrm{C}$ at noon and under constant short-day conditions of $8 \mathrm{~h}$ photoperiod. Within the

123 environmental chambers, each colony was connected to a separate flight arena with an

124 individually controllable LED light source (36 cold white (6500K) LEDs and 6 UV-LEDs;

$125 \sim 2000$ lx illuminance), diffused with a sandblasted glass cover (Fig. 1). Honey bees could enter

126 the flight arena via a short tunnel. The tunnels were covered with reflective aluminium foil to

127 increase the amount of light that passes from the arena into the hive box to be perceived by

128 honey bees in the winter cluster. To identify effects of ambient temperature and photoperiod on

129 brood rearing activity, individual temperature and light regimes were started at $28^{\text {th }}$ January. All

130 applicable institutional and national guidelines for the care and use of animals were followed.

132 Temperature regimes

133 To investigate the effects of ambient temperature on brood rearing in honey bee winter clusters,

134 colonies were distributed equally into two temperature treatments (Fig. 2): 
135 (a) In environmental chamber $A$ the temperature remained at constant cold conditions of $0^{\circ} \mathrm{C} \pm$

$1363^{\circ} \mathrm{C}$ for 78 days after the start of the experiment as a control.

137 (b) Imitating a spell of warm weather, ambient temperature in environmental chamber B was 138 gradually upregulated to $11^{\circ} \mathrm{C} \pm 3^{\circ} \mathrm{C}$ after day 30 and after a warm period of 15 days, ambient 139 temperature dropped again to cold conditions of $0^{\circ} \mathrm{C} \pm 3^{\circ} \mathrm{C}$.

140 At day 78 and day 75 respectively the experiment was terminated and all colonies were released

141 from the environmental chambers and placed outside on a meadow at the campus of the

142 University of Würzburg at $6^{\text {th }}$ March 2015.

144 Light regimes

145 To check for effects of total photoperiod and photoperiod changes on brood rearing activity 146 colonies were assigned to three different photoperiod regimes (Fig. 2):

147 (a) Constant photoperiod: short-day conditions with an 8h light to $16 \mathrm{~h}$ dark cycle (8:16 LD),

148 which reflects the minimum day length in Central Europe and served as control treatment.

149 (b) Increasing photoperiod: steadily increasing duration of photoperiod, starting at 8:16 LD with 150 daily increase of $2 \mathrm{~min} 40 \mathrm{sec}$, which is a simplified but realistic scenario for Central Europe 151 between winter and summer solstice.

152 (c) Peaking photoperiod: photoperiod starting at 8:16 LD with a steady increase in photoperiod 153 of $10 \mathrm{~min} 40 \mathrm{sec}$ each day for 45 days to a maximum of 16:8 LD, followed by a steady decrease of 154 10min 40sec each day until the end of the experiment. This additional experimental scenario was 
155 introduced to allow examination of effects of photoperiod change independently from

156 photoperiod duration.

157

158 Tracking of comb temperature

159 Comb temperature in each colony was tracked by eight thermo-sensors (Maxim Integrated

160 DS1921G-F5 Thermochron iButton; $0.5^{\circ} \mathrm{C}$ resolution) that were embedded into the central wax

161 layer of combs to keep track of winter cluster activity (Fig. 1). Temperature was measured in 3-

162 hour intervals. At each interval, the sensor that measured the highest temperature was considered

163 as being closest to the centre of the winter cluster and used in the statistical analyses as measure

164 for comb temperature. When the in-hive temperature was up regulated to over $30^{\circ} \mathrm{C}$ and the daily

165 variation was not higher than $1.5^{\circ} \mathrm{C}$, colonies were defined as brood rearing (Kronenberg \&

166 Heller 1982). Ambient temperature for each colony was tracked via a thermo-sensor in the

167 respective flight arena.

168

169 Statistics

170 The statistical software R version 3.4.0 (R Core Team 2017) was used for data analysis. For each

171 observation day colonies were classified as brood rearing if the comb temperature was stable

172 with a daily amplitude of comb temperature $\leq 1.5^{\circ} \mathrm{C}$. A linear-mixed effects model was used to

173 test for the effects of ambient temperature and comb temperature variability on mean comb

174 temperature. Data was square root transformed to meet requirements of normal distribution. A

175 contrast matrix was used post hoc to test for differences between individual factor levels. We

176 used a generalized linear mixed-effects model for binomial data to test for interacting effects of 
177 temperature phase and light regime on the proportion of days during which brood rearing

178 occurred in colonies for each temperature phase and light regime combination. Only data from

179 environmental chamber B was used to analyse interactions between the environmental factors.

180 Temperature in chamber A remained constant at all times, making its data inadequate to assess

181 interactions. Differences between individual levels of factors were tested post hoc using Tukey's

182 test. The effect of photoperiod duration on the proportion of colonies that were rearing brood for 183 each day was tested, using a generalized linear mixed-effects model for binomial data. A linear

184 mixed-effects model was used to test for effects of direction of photoperiod change on 185 probability of brood rearing. We used a linear mixed-effects model to test for the effect of the direction of change of photoperiod on the probability of brood rearing. Only data from colonies that were kept at constant low temperature conditions was used to test for effects of photoperiod duration or direction of change of photoperiod on brood rearing status. The effect of time spent within the experiment on proportion of colonies that reared brood was tested using a generalized linear-mixed effects model for binomial data. This was done for a subset of colonies under constant cold and short-day conditions, as well as for all colonies, regardless of treatment combination. Colony ID was included as random factor in all models. Benjamini-Hochberg correction for multiple testing was applied for all post hoc tests (Benjamini \& Yekutieli 2001). Model residuals were inspected visually to confirm normality and homoscedasticity. Sample sizes and degreed of freedom were based on numbers of observation days. For all models, a significance level $(\alpha)$ of 0.05 was considered.

One colony under constant cold temperature and peaking photoperiod conditions was removed

198 from the statistical analyses because the temperature profiles revealed that it was still rearing 199 brood at the beginning of the experiment and continued to rear brood during the whole 
200

201

202

203

204

205

206

207

208

209

210

211

212

213

214

215

216

217

218

219

220

221

experiment. Three colonies within environmental chamber A and one colony within

environmental chamber B were removed from the analyses because they died early in the experiment. This left the treatment combination of constant cold temperature and increasing photoperiod with only two colonies. As data from all colonies within chamber A were combined to analyze effects of photoperiod, this should not have compromised statistical analysis. All other treatment combinations were left with at least three colonies. Four colonies were lost during the second half of the experiment. Observation days from these colonies were included into the analyses until temperature profiles became unstable and eventually dropped to ambient temperature level. A total of 1325 observation days from 19 colonies contributed to the statistical analysis.

\section{Results}

\section{Variability of comb temperature}

Stability of comb temperature and mean ambient temperature had interacting effects on mean comb temperature measured in the winter cluster (interaction: stability of comb temperature $\times$ mean ambient temperature: $F_{1,1271.85}=8.26 ; p=0.004 ; n=1325$ observation days from 19 colonies; Fig. 3). When comb temperature was stable (i.e. daily amplitude of comb temperature $\leq$ $1.5^{\circ} \mathrm{C}$ ) mean comb temperature was significantly higher than when comb temperature was variable (i.e. daily amplitude of comb temperature $>1.5^{\circ} \mathrm{C} ; z=6.19, p<0.0001$ ) and no longer affected by ambient temperature (Tukey's post hoc test: $z=1.60, p=0.111$ ). This state of stable comb temperature was considered a strong indicator of brood rearing activity. Stable comb temperature was used to identify brood rearing activity in colonies for all following analyses. 
222 When comb temperature was variable, mean comb temperature was negatively correlated with

223 ambient temperature (Tukey's post hoc test: $z=-3.35, p=0.001)$. Colonies were considered to

224 not rear significant amounts of brood in this state.

Effects of ambient temperature and light regime on brood rearing activity

227

228

229

230

231

232

233

234

235

236

237

238

239

240

241

242

There was a significant interaction between the effects of ambient temperature and light regime on the proportion of days during which colonies reared brood (i.e. daily amplitude of comb temperature $\leq 1.5^{\circ} \mathrm{C}$; data from environmental chamber $\mathrm{B}$; temperature conditions $\mathrm{x}$ light regime: $F_{4,34}=2.26, p<0.023 ; n=752$ observation days from 11 colonies; Fig. 4). Under shortday conditions, the probability of brood rearing increased when ambient temperature was increased $\left(11^{\circ} \mathrm{C} \pm 3^{\circ} \mathrm{C}\right.$; Tukey's post hoc test: $\left.z=4.34, p<0.001\right)$. A drop of ambient temperature back to $0^{\circ} \mathrm{C} \pm 3^{\circ} \mathrm{C}$ after the warm period did not significantly reduce the brood rearing activity (Tukey's post hoc test: $z=-1.85, p=0.146$ ). Surprisingly, there was no significant effect of ambient temperature on brood rearing under conditions of increasing or peaking photoperiod.

Under constant low temperature conditions of $0^{\circ} \mathrm{C} \pm 3^{\circ} \mathrm{C}$ within environmental chamber $\mathrm{A}$ the duration of photoperiod had no significant effect on the proportion of colonies that reared brood $\left(F_{1,570}=0.10, p=0.755 ; n=573\right.$ observation days from eight colonies; Fig. 5$)$. The direction of change of photoperiod had no significant effect on the proportion of days during which colonies reared $\operatorname{brood}\left(F_{2,8.09}=1.72, p=0.238 ; n=573\right.$ observation days from eight colonies; Fig. 6).

Independent of the tested environmental factors, the proportion of colonies that reared brood (i.e. daily amplitude of comb temperature $\leq 1.5^{\circ} \mathrm{C}$ ) significantly increased over time in both a subset 
244 of colonies that were all kept at constant cold and short-day conditions without further

245 environmental cues $\left(F_{1,222}=3.81, p=0.045 ; n=225\right.$ observation days from three colonies; Fig.

$2467)$ as well as across all treatments $\left(F_{1,1320}=24.47, p<0.0001 ; n=1325\right.$ observation days from

24719 colonies).

249 Discussion

250 We demonstrated that tracking comb temperature with thermosensors is a valuable minimally

251 invasive method to track brood rearing activity in honey bee hives, even during winter. Applying

252 this method, we could show that onset of brood rearing in honey bee winter clusters is affected

253 by environmental conditions. In our experimental setting, colonies were more often found to rear

254 brood after ambient temperature was increased than during the preceding cold period. Neither

255 duration of photoperiod nor the direction of daily change of photoperiod alone had a significant

256 effect on brood rearing activity within winter clusters. However, the light regime did affect the

257 response of winter clusters to temperature changes. There was only a significant response to

258 temperature increase in colonies that were kept at constant short-day. While interacting effects of

259 different abiotic conditions could help to minimise the risk of premature brood onset, our results

260 suggest that increasing winter temperatures and more frequent spells of warm weather due to

261 global climate change could result in advanced timing of brood onset. This might cause

262 mismatches with the environment with negative consequences for honey bee colony fitness and

263 pollination services. Independent of the measured environmental factors, onset of brood rearing

264 also became more probable with time, which could indicate the involvement of an internal clock. 
265 This study is, to the best of our knowledge, the first where individual and combined effects of

266 ambient temperature and photoperiod on honey bee winter cluster activity were investigated

267 under controlled conditions. Our experimental design allowed us to keep track of honey bee

268 colony thermoregulation and thereby brood rearing activity under defined environmental

269 conditions and without disturbing the colonies. We provide an alternative approach to earlier

270 studies which were either extremely invasive (Avitabile 1978) or not conducted under winter

271 conditions (Fluri \& Bogdanov 1987; Harris 2009; Kefuss 1978). Indirectly detecting brood

272 rearing by tracking thermoregulatory activity via thermo-sensors within the comb wax allowed

273 us to investigate honey bee colonies under winter conditions without severely affecting honey

274 bee behaviour and colony health. By analysing patterns of daily comb temperature variation, we

275 could identify days where colonies performed intensive thermoregulation. A daily comb

276 temperature amplitude within the winter cluster of maximally $1.5^{\circ} \mathrm{C}$, despite a considerably

277 higher ambient temperature amplitude, was accompanied by an increase of mean comb

278 temperature to more than $30^{\circ} \mathrm{C}$. Further, in this state mean comb temperature was not affected by

279 mean ambient temperature. Such conditions were previously measured in the presence of capped

280 brood within the winter cluster (Kronenberg \& Heller 1982). When colonies rear brood, the

281 cluster core temperature is highly important and needs to be stable to allow for a proper

282 development of brood (Jones et al. 2005; Tautz et al. 2003). We conclude that daily temperature

283 amplitude measured within the winter cluster is a good predictor for brood rearing activity. It is

284 important to keep in mind that the spatial resolution of temperature data was limited and small

285 brood nests might not have been detected in all cases. In fact, even in temperate zones

286 continuous brood rearing during winter could be common, albeit at very limited extent (Avitabile

287 1978; Harris 2009; Szabo 1993). Once the brood nest grows and colonies start to rear brood at 
288 considerable amounts, this can be expected to be reflected in the temperature data obtained from

289 our experimental setting. Although some uncertainty about the status of the colony will remain,

290 we argue that this indirect method is preferable over the much more invasive method of

291 disrupting the cluster to visually assess brood status.

292 In our experiment brood rearing activity was rarely detected under cold environmental conditions

293 (i.e. -3 to $+3{ }^{\circ} \mathrm{C}$ ). Once ambient temperature increased, colonies were more often found to rear

294 brood. The effect of ambient temperature on brood rearing activity is not surprising. The energy

295 demand of thermoregulation necessary for brood rearing increases with decreasing ambient

296 temperature (Kronenberg \& Heller 1982). As the resources needed to fuel thermoregulation are

297 strongly limited, honey bee colonies should refrain from brood rearing under cold environmental

298 conditions (Seeley \& Visscher 1985; Southwick 1991). With increasing ambient temperature

299 thermoregulation, and hence brood rearing, becomes less cost intensive and more viable, even

300 when colonies need to solely rely on storages. Ambient temperature was previously also shown

301 to have a strong effect on timing of increased thermoregulation after hibernation in ants of the

302 Formica-group (Rosengren et al. 1987) as well as timing of hibernation and emergence in

303 mammals (Körtner \& Geiser 2000; Meyer et al. 2016; Mrosovsky 1990; Ruf et al. 1993). After

304 colonies started to rear brood, a drop of ambient temperature did not immediately cause them to

305 stop. Pheromones released by honey bee larvae are known to stimulate brood rearing and

306 associated behaviours in workers (Pankiw et al. 2004; Sagili \& Pankiw 2009). Hence, the mere

307 presence of brood might have stimulated the workers to continue brood care and keeping the

308 brood combs warm, even when mean ambient temperature was as cold as $0^{\circ} \mathrm{C}$. This may cause

309 honey storages to run out quickly and leave colonies starving. It is possible that, once triggered,

310 only a disruption of honey or pollen stores will ultimately force a stop of brood rearing activity. 
311 It is important to note that, despite a relatively large increase of ambient temperature, the

312 proportion of days during which we detected brood rearing activity in our experiment only

313 increased by about $30 \%$. This reaction was weaker than expected and suggests that further

314 factors are involved in the timing of brood onset.

315 Our data revealed that photoperiod in isolation had no effect on brood rearing activity. Neither

316 duration of photoperiod nor direction of change of photoperiod affected brood rearing under cold

317 conditions. It might be possible that honey bees are not able to measure photoperiod when

318 densely packed within the winter cluster. It has been suggested for mammals which hibernate in

319 shelters and therefore have limited access to day light, that ambient temperature would be the

320 most appropriate stimulus or zeitgeber for timing of emergence after hibernation (Davis 1977;

321 Körtner \& Geiser 2000; Michener 1977; Mrosovsky 1980; Murie \& Harris 1982). However, in

322 our experiment light regime did alter the response of honey bee colonies during warmer

323 conditions, when winter clusters were probably less dense and workers could leave the cluster.

324 Adult emergence, reproduction and oviposition in the marine midge Cluneo marinus is also

325 known to be controlled by two environmental factors that need to occur in unison (Kaiser \&

326 Heckel 2012). Increasing ambient temperature affected brood onset only at constant short-day

327 conditions of $8 \mathrm{~h}$ photoperiod, but not in the other two light regimes in which photoperiod was

328 considerably longer (about $12 \mathrm{~h}$ to $18 \mathrm{~h}$, depending on light regime) and increasing. These

329 findings are not in line with suggestions that a short photoperiod elicits cannibalization of eggs

330 and hence inhibits brood rearing activity (Cherednikov 1967; Woyke 1977). Several studies

331 proposed that, irrespective of current duration of photoperiod, an increase in photoperiod has a

332 positive effect on brood rearing activity while a decrease of photoperiod negatively affects brood

333 rearing (Avitabile 1978; Kefuss 1978). The inhibitory effect of photoperiod treatments with 
334 increasing photoperiod on brood rearing under warm conditions in our study does not support

335 these findings. However, most of the previous studies that investigated the effect of photoperiod

336 on brood rearing activity either did not investigate brood rearing activity in winter (Fluri \&

337 Bogdanov 1987; Kefuss 1978) or did not control for other environmental conditions that might

338 have affected brood rearing activity like ambient temperature (Avitabile 1978; Fluri \& Bogdanov

339 1987). It was previously shown that brood rearing activity in colonies that were kept at

340 constantly low mean ambient temperature of $6^{\circ} \mathrm{C}$ were not affected by photoperiod (Harris

341 2009). This is in line with our findings, that photoperiod matters only under warm conditions.

342 Fluri \& Bogdanov (1987) failed to find an effect of photoperiod under warm conditions, but

343 investigated the effect of artificial shortening of the photoperiod in summer when colonies were

344 already rearing large amounts of brood. Under these circumstances the effect of photoperiod

345 might be reduced (but see Kefuss (1978)). Due to the experimental settings, we cannot

346 disentangle if it was the longer duration of photoperiod or the fact that photoperiod increased that

347 reduced brood rearing under warm conditions. It also remains to be investigated if a decrease of

348 photoperiod during a warm period would affect brood rearing. Our results indicate that

349 photoperiod was used as additional cue and might help to prevent premature brood onset due to

350 spells of warm weather. However, according to our hypothesis, short photoperiod was expected

351 to inhibit brood rearing while increasing photoperiod should have promoted brood rearing

352 activity and not vice versa. This illustrates that further experiments on combined effects of

353 temperature and photoperiod are needed. It is important to note that honey bees show

354 considerable geographical variation with a number of subspecies and locally adapted ecotypes

355 (Meixner et al. 2013). We used A. mellifera carnica as it is one of the most commonly used

356 subspecies in central Europe and of high economical relevance. It is highly productive and 
357 expected to increase brood rearing activity relatively fast once conditions seem favourable. To

358 which extent other subspecies and ecotypes might differ in their reaction to environmental cues

359 remains to be investigated.

360 In addition to photoperiod and ambient temperature also elapsed time affected brood rearing in

361 the honey bee colonies. Brood rearing activity was detected with increasing frequency over time

362 and we observed brood rearing activity in one colony even at constant short-day and cold

363 conditions. This suggests that colonies recommence brood rearing at some point regardless of

364 environmental conditions. It has been shown for mammals that a circannual rhythmicity

365 underlies the timing of hibernation and seasonal torpor, which can be entrained by photoperiod,

366 ambient temperature and food-availability, but does not rely on these external zeitgebers (Collins

367 \& Cameron 1984; Heldmaier \& Steinlechner 1981; Körtner \& Geiser 2000; Mrosovsky 1986;

368 Steinlechner et al. 1983; Wang 1988). Timing of honey bee brood rearing activity might also be

369 controlled by an internal clock. The queen is the only individual of a colony that can live for

370 several years and thus feature a true circannual clock. Previous work has shown that not only

371 egg-laying activity but also the size of queen ovaries changes over the seasons, which might be

372 controlled by an endogenous rhythm (Shehata et al. 1981). Potential changes in queen

373 pheromone releases related to an increasing ovary size might then prime the colony's workers for

374 brood caring in late winter as queen pheromones are involved in the regulation of worker tasks

375 (Slessor et al. 2005). Another reason for increased probability of brood onset over time might be

376 the build-up of moisture within colonies. It was proposed that the humidity in colonies affects

377 brood rearing activity and brood may serve to bind moisture generated by the metabolic activity

378 of colonies which may otherwise be harmful (Omholt 1987). Humidity within the different

379 colonies might have varied and was not tracked during the experiment. The availability of 
380 resources might be another highly important factor for timing of brood rearing. Colonies that

381 were supplemented with pollen in spring were previously found to start brood rearing earlier in

382 the year (Mattila \& Otis 2006). It has also been shown that the nutritional status of individuals

383 and food-availability can affect the response to environmental cues for timing of hibernation in

384 mammals (Norquay \& Willis 2014; Ruf et al. 1993) and the thermoregulation in Formica-ants

385 (Rosengren et al. 1987).

387 Conclusions

We conclude that brood rearing activity in hibernating honey bee colonies is highly sensitive to

climatic conditions. Ambient temperature seems to be an important trigger for brood onset, but

responses to temperature can be modulated by photoperiod. Climate change and associated more

frequent warm weather events during winter (IPCC 2014) have the potential to disrupt the

synchronization between the seasonal timing of brood onset in honey bee colonies and flowering phenology. This can have profound negative consequences for colony fitness.

\section{Acknowledgements}

396

397

398

399

400

401

We would like to thank Prof. Dr. Bernd Grünewald and Beate Springer from the Institut für Bienenkunde, Oberursel, Frankfurt University, for expert support and provision of inseminated sister-queens for the experiment. We thank Susanne Schiele for her excellent assistance with the beekeeping, Thomas Igerst and Norbert Schneider for assistance in the development and design of the experimental bee hive system as well as for technical support during the experiment and Dr. Conrad Wild for programming and supporting the control system. 
402

403

404

405

406

407

408

409

410

411

412

413

414

415

416

417

418

419

420

421

422

423

\section{References}

Avitabile A. 1978. Brood rearing in honeybee colonies from late autumn to early spring. Journal of Apicultural Research 17:69-73. 10.1080/00218839.1978.11099905

Benjamini Y, and Yekutieli D. 2001. The Control of the False Discovery Rate in Multiple Testing under Dependency. The Annals of Statistics 29:1165-1188.

Bradshaw WE, and Holzapfel CM. 2007. Evolution of animal photoperiodism. Annual Review of Ecology Evolution and Systematics. Palo Alto: Annual Reviews, 1-25.

Cherednikov A. 1967. Photoperiodism in the honeybee, Apis mellifera L. Hymenoptera, Apidae), Entom Review 46:33-37.

Collins VE, and Cameron DM. 1984. The effects of diet and photoperiod on hibernation in the woodland jumping mouse, Napaeozapus insignis (Miller). Canadian Journal of Zoology 62:1938-1945. 10.1139/z84-283

Davis DE. 1977. Role of ambient temperature in emergence of woodchucks (Marmota monax) from hibernation. American Midland Naturalist 97:224-229. 10.2307/2424700

Esch H. 1964. Über den Zusammenhang zwischen Temperatur, Aktionspotentialen und Thoraxbewegungen bei der Honigbiene (Apis mellifica L.). Zeitschrift für Vergleichende Physiologie 48:547-551. 10.1007/bf00348848

Fahrenholz L, Lamprecht I, and Schricker B. 1989. Thermal investigations of a honey bee colony: thermoregulation of the hive during summer and winter and heat production of members of different bee castes. Journal of Comparative Physiology B 159:551-560. 10.1007/bf00694379 
424 Fluri P, and Bogdanov S. 1987. Effects of Artificial Shortening of the Photoperiod on Honeybee 425 (Apis Mellifera) Polyethism. Journal of Apicultural Research 26:83-89. $10.1080 / 00218839.1987 .11100742$

427

428

429

430

431

432

433

434

435

436

437

438

439

440

441

442

443

444

Harris JL. 2009. Development of honey bee colonies on the Northern Great Plains of North America during confinement to winter quarters. Journal of Apicultural Research 48:8590. 10.3896/IBRA.1.48.2.01

Heldmaier G, and Steinlechner S. 1981. Seasonal control of thermogenesis by photoperiod and ambient temperature in the Djungarian hamster, Phodopus sungorus. Cryobiology 18:9697.

IPCC. 2014. Climate Change 2014: Synthesis Report. Contribution of Working Groups I, II and III to the Fifth Assessment Report of the Intergovernmental Panel on Climate Change. Geneva, Switzerland: IPCC.

Jones JC, Helliwell P, Beekman M, Maleszka R, and Oldroyd BP. 2005. The effects of rearing temperature on developmental stability and learning and memory in the honey bee, Apis mellifera. Journal of Comparative Physiology A 191:1121-1129. 10.1007/s00359-0050035-z

Jones JC, Myerscough MR, Graham S, and Oldroyd BP. 2004. Honey Bee Nest Thermoregulation: Diversity Promotes Stability. Science 305:402-404. 10.1126/science. 1096340

Jones JC, and Oldroyd BP. 2006. Nest thermoregulation in social insects. Advances in Insect Physiology 33:153-191. 10.1016/S0065-2806(06)33003-2 
445 Kaiser TS, and Heckel DG. 2012. Genetic Architecture of Local Adaptation in Lunar and

446 Diurnal Emergence Times of the Marine Midge Clunio marinus (Chironomidae, Diptera). PLOS ONE 7:e32092. 10.1371/journal.pone.0032092

448 Kefuss JA. 1978. Influence of photoperiod on the behaviour and brood-rearing activities of

449

450

451

452

453

454

455

456

457

458

459

460

461

462

463

464

465

466

467

honeybees in a flight room. Journal of Apicultural Research 17:137-151.

$10.1080 / 00218839.1978 .11099919$

Körtner G, and Geiser F. 2000. The temporal organization of daily torpor and hibernation: circadian and circannual rhythms. Chronobiology International 17:103-128.

10.1081/CBI-100101036

Kronenberg F, and Heller HC. 1982. Colonial Thermoregulation in Honey Bees (Apis mellifera). Journal of Comparative Physiology B 148:65-76.

Mattila HR, and Otis GW. 2006. Influence of Pollen Diet in Spring on Development of Honey Bee (Hymenoptera: Apidae) Colonies. Journal of Economic Entomology 99:604-613. $10.1603 / 0022-0493-99.3 .604$

Meixner MD, Pinto MA, Bouga M, Kryger P, Ivanova E, and Fuchs S. 2013. Standard methods for characterising subspecies and ecotypes of Apis mellifera. Journal of Apicultural Research 52:1-28. 10.3896/IBRA.1.52.4.05

Meyer GA, Senulis JA, and Reinartz JA. 2016. Effects of temperature and availability of insect prey on bat emergence from hibernation in spring. Journal of Mammalogy 97:1623-1633. 10.1093/jmammal/gyw126

Michener GR. 1977. Effect of climatic conditions on annual activity and hibernation cycle of Richardson's ground squirrels and Columbian ground squirrels. Canadian Journal of Zoology-Revue Canadienne De Zoologie 55:693-703. 10.1139/z77-091 
468 Mrosovsky N. 1980. Circannual cycles in Golden-manteled ground squirrels: phase-shift 469 produced by low temperatures. Journal of Comparative Physiology 136:349-353.

470 Mrosovsky N. 1986. Thermal effects on the periodicity, phasing, and persistence of circannual $471 \quad$ cycles. Living in the cold: physiological biochemical adaptations (eds HC Heller, XJ Musacchia \& LCH Wang):403-410.

473

474

Mrosovsky N. 1990. Circannual cycles in golden-mantled ground squirrels: fall and spring cold pulses. Journal of Comparative Physiology A 167:683-689. 10.1007/bf00192662

Murie JO, and Harris MA. 1982. Annual Variation of Spring Emergence and Breeding in Columbian Ground Squirrels (Spermophilus columbianus). Journal of Mammalogy $63: 431-439.10 .2307 / 1380440$

Norquay KJO, and Willis CKR. 2014. Hibernation phenology of Myotis lucifugus. Journal of Zoology 294:85-92. 10.1111/jzo.12155

Omholt SW. 1987. Why honeybees rear brood in winter. A theoretical study of the water conditions in the winter cluster of the honeybee, Apis mellifera. Journal of Theoretical Biology 128:329-337. 10.1016/S0022-5193(87)80075-9

Pankiw T, Roman R, Sagili RR, and Zhu-Salzman K. 2004. Pheromone-modulated behavioral suites influence colony growth in the honey bee (Apis mellifera). Naturwissenschaften 91:575-578. 10.1007/s00114-004-0568-y

Potts SG, Imperatriz-Fonseca V, Ngo HT, Aizen MA, Biesmeijer JC, Breeze TD, Dicks LV, Garibaldi LA, Hill R, Settele J, and Vanbergen AJ. 2016. Safeguarding pollinators and their values to human well-being. Nature 540:220-229. 10.1038/nature20588

R Core Team. 2017. R: A language and environment for statistical computing. Vienna, Austria: R Foundation for Statistical Computing. 
491 Rosengren R, Fortelius W, Lindström K, and Luther A. 1987. Phenology and causation of nest 492 heating and thermoregulation in red wood ants of the Formica rufa group studied in 493 coniferous forest habitats in southern Finland. Annales Zoologici Fennici 24:147-155.

494 Ruf T, Stieglitz A, Steinlechner S, Blank JL, and Heldmaier G. 1993. Cold exposure and food 495 496 497 restriction facilitate physiological responses to short photoperiod in Djungarian hamsters (Phodopus sungorus). Journal of Experimental Zoology 267:104-112. $10.1002 /$ jez.1402670203

Sagili RR, and Pankiw T. 2009. Effects of Brood Pheromone Modulated Brood Rearing Behaviors on Honey Bee (Apis mellifera L.) Colony Growth. Journal of Insect Behavior 22:339-349. 10.1007/s10905-009-9176-1

Schenk M, Krauss J, and Holzschuh A. 2018. Desynchronizations in bee-plant interactions cause severe fitness losses in solitary bees. Journal of Animal Ecology 87:139-149.

$$
10.1111 / 1365-2656.12694
$$

Seeley TD, and Visscher PK. 1985. Survival of honeybees in cold climates: the critical timing of colony growth and reproduction. Ecological Entomology 10:81-88. 10.1111/j.13652311.1985.tb00537.x

Shehata SM, Townsend GF, and Shuel RW. 1981. Seasonal Physiological Changes in Queen and Worker Honeybees. Journal of Apicultural Research 20:69-78. $10.1080 / 00218839.1981 .11100475$

Slessor KN, Winston ML, and Le Conte Y. 2005. Pheromone Communication in the Honeybee (Apis mellifera L.). Journal of Chemical Ecology 31:2731-2745. 10.1007/s10886-005$7623-9$ 
513 Southwick EE. 1985. Allometric relations, metabolism and heart conductance in clusters of 514 honey bees at cool temperatures. Journal of Comparative Physiology B 156:143-149. $10.1007 / \mathrm{bf00692937}$

516 Southwick EE. 1991. The colony as a thermoregulating superorganism. Wallingford, UK: CAB $517 \quad$ International.

518 Stabentheiner A. 2005. Individuelle und soziale Thermoregulation der Honigbiene. $519 \quad$ Entomologica Austriaca 12:13-22.

520 Stabentheiner A, Kovac H, and Brodschneider R. 2010. Honeybee Colony Thermoregulation 521 Regulatory Mechanisms and Contribution of Individuals in Dependence on Age, Location and Thermal Stress. PLOS ONE 5:e8967. 10.1371/journal.pone.0008967

523 Steinlechner S, Heldmaier G, and Becker H. 1983. The seasonal cycle of body weight in the 524 Djungarian hamster: photoperiodic control and the influence of starvation and melatonin. Oecologia 60:401-405. 10.1007/bf00376859

Szabo TI. 1993. Brood rearing in outdoor wintered honey bee colonies. American Bee Journal 133:579-580.

528

529

530

531

532 533

534

Tautz J, Maier S, Groh C, Rössler W, and Brockmann A. 2003. Behavioral performance in adult honey bees is influenced by the temperature experienced during their pupal development. Proceedings of the National Academy of Sciences 100:7343-7347. 10.1073/pnas. 1232346100

van Asch M, and Visser ME. 2007. Phenology of Forest Caterpillars and Their Host Trees: The Importance of Synchrony. Annual Review of Entomology 52:37-55. 
535 Visser ME. 2013. Phenological shifts in animals under contemporary climate change. In: Levin 536 SA, ed. Encyclopedia of Biodiversity: Elsevier, $716-727$.

537 Visser ME, Both C, and Lambrechts MM. 2004. Global Climate Change Leads to Mistimed

538 Avian Reproduction. Advances in Ecological Research 35:89-110. 10.1016/S0065$539 \quad 2504(04) 35005-1$

540 Wang LCH. 1988. Mammalian Hibernation: An Escape from the Cold. Advances in 541 Comparative and Environmental Physiology. Berlin, Heidelberg: Springer Berlin $542 \quad$ Heidelberg, 1-45.

543 Williams CM, Henry HAL, and Sinclair BJ. 2015. Cold truths: how winter drives responses of 544 terrestrial organisms to climate change. Biological Reviews 90:214-235.

$545 \quad 10.1111 /$ brv.12105

546 Woyke J. 1977. Cannibalism and Brood-Rearing Efficiency in the Honeybee. Journal of $547 \quad$ Apicultural Research 16:84-94. 10.1080/00218839.1977.11099866 


\section{Figure 1}

Experimental hive setup.

(A) Honey bee colonies were placed into experimental hive boxes, based on two miniPlusstyrofoam boxes, each with six comb frames. Hive boxes were connected to a third styrofoam box that served as flight arena via a short tunnel. (B) An array of LEDs was installed into each flight arena and allowed to implement individual light regimes for each colony. (C) A thermo-sensor was installed into the wax of the second to fourth comb on both hive levels, in a way that allowed to track temperature on both sides of the comb. (D) Within each hive level thermo-sensors on consecutive combs were installed in alternating order, either between the left and the middle third of the comb or between the right and the middle third of the comb. This pattern was reversed on the other hive level, to maximise the area covered by thermo-sensors. This allowed to keep track of thermoregulatory activity within the experimental colonies at relative high spatial resolution without disturbing or disrupting winter clusters. A photoelectric barrier within the tunnel between hive box and arena connected to a data logger allowed to track honey bee traffic between hive box and arena. All colonies were placed into two dark environmental chambers. A wire mesh bottom in the flight arena and hive box and metal lid on the flight arena top facilitated temperature exchange through convection and conduction to make sure that the honey bee colonies were not isolated from ambient temperatures. Photo credit: Fabian Nürnberger. 


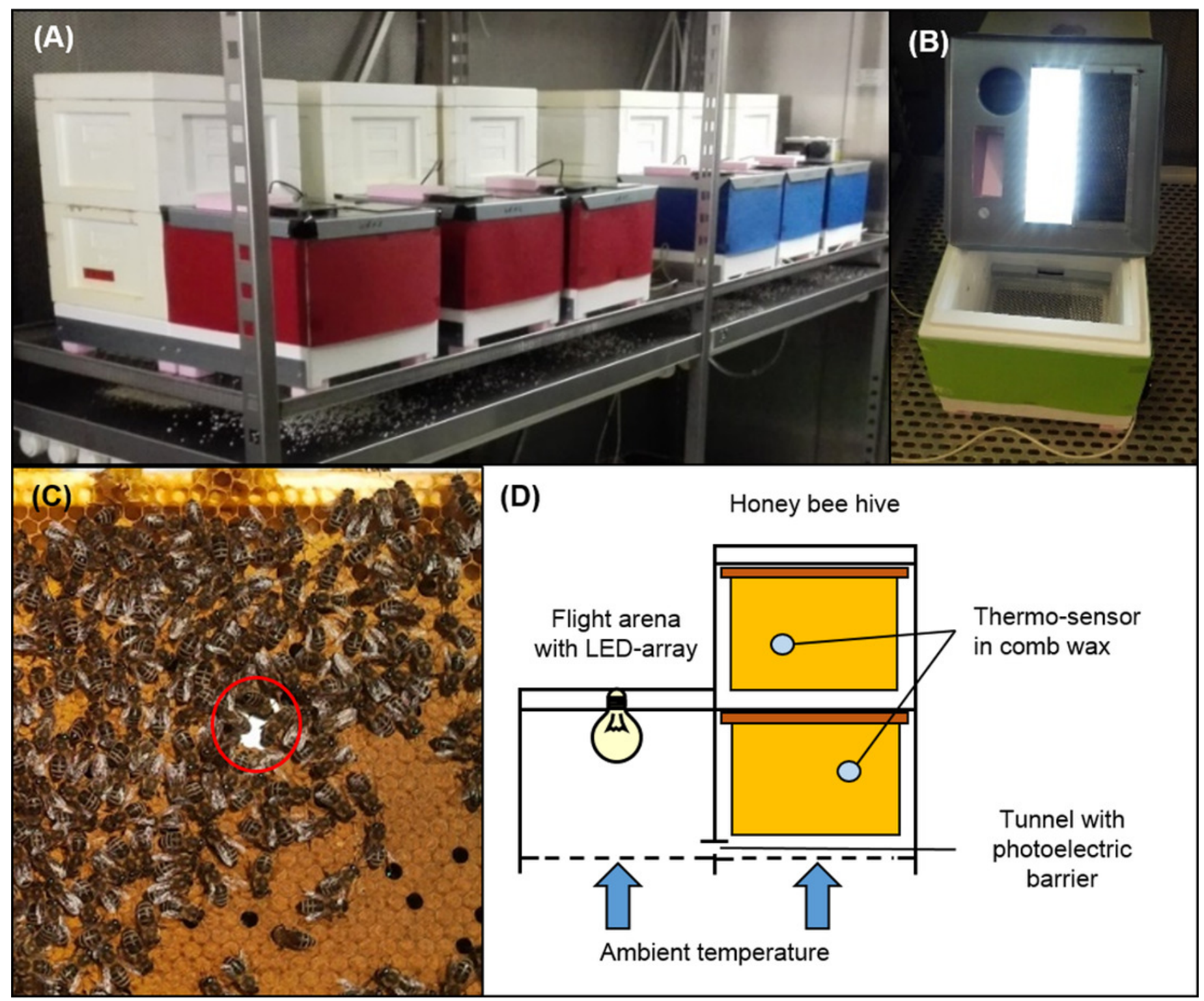




\section{Figure 2}

Temperature and light regimes.

At the start of the experiment, 24 honey bee colonies within experimental hive boxes were distributed equally among two environmental chambers (environmental chamber $A$ and $B$ ) that differed in ambient temperature regime. Each colony was connected to its own flight arena with individually controllable light regime and distributed among three different light regimes (constant, increasing and peaking photoperiod) independently from ambient temperature regime. This allowed us to test for effects of ambient temperature and photoperiod in isolation as well as for interacting effects on brood rearing activity in honey bee winter clusters. Grey area: daily amplitude of ambient temperature. 

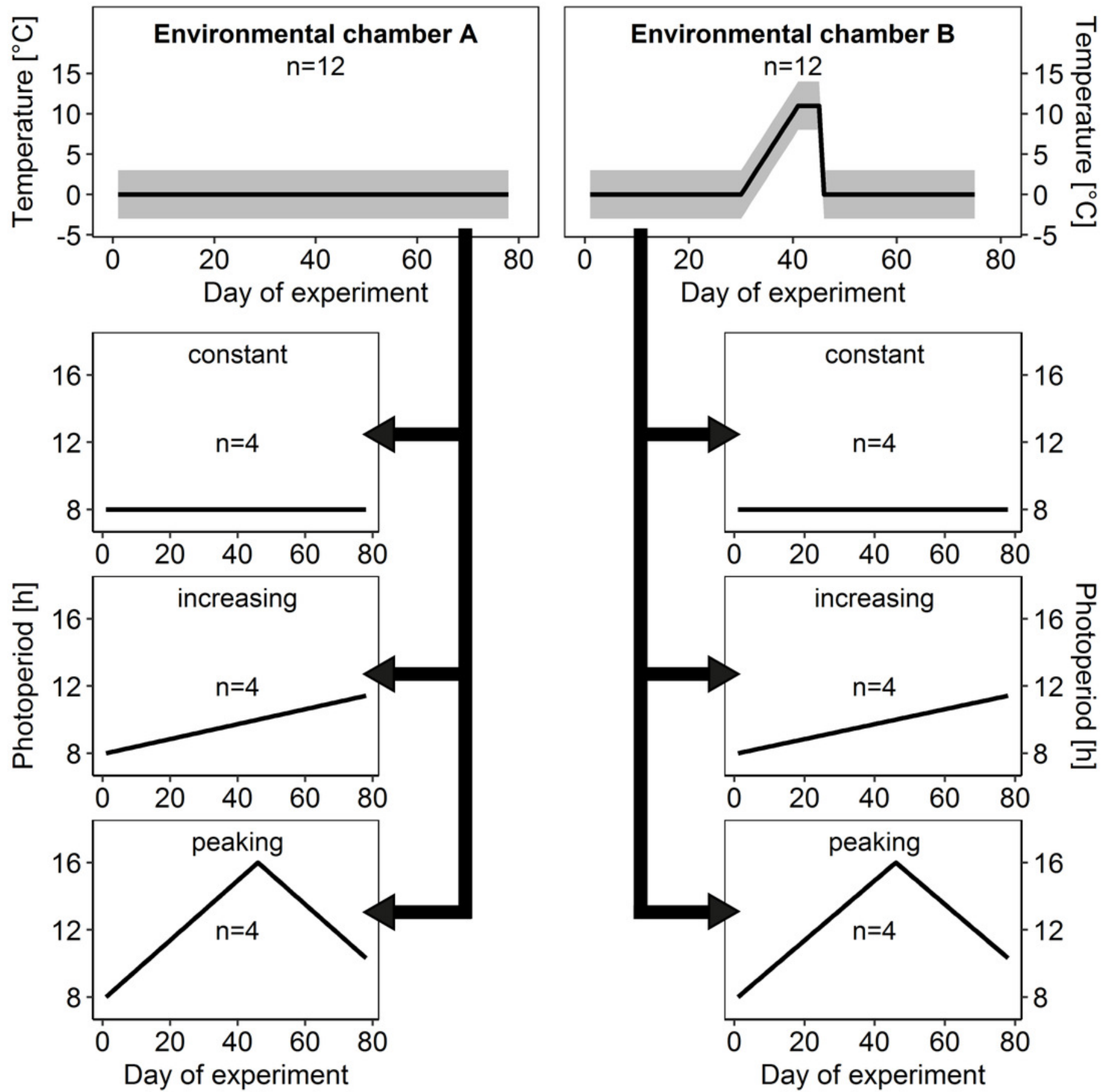


\section{Figure 3}

Decreased daily variation of comb temperature in honey bee colonies is accompanied by a significant increase of mean comb temperature which is no longer significantly affected by ambient temperature.

Linear mixed-effects model: stability of comb temperature $\times$ ambient temperature: $F_{1,1271.85}=$ $8.26 ; p=0.004)$. Blue line: stable comb temperature, defined by daily amplitude of comb temperature $\leq 1.5^{\circ} \mathrm{C}$; black line: variable comb temperature, defined by daily amplitude of comb temperature $>1.5^{\circ} \mathrm{C}$. Grey areas: $95 \%$ confidence intervals. $n=1325$ observation days from 19 colonies. Tukey's test with Benjamini-Hochberg correction for post hoc analysis of effect of ambient temperature on mean comb temperature. **: $p<0.01 ; n s: p>0.05$. 


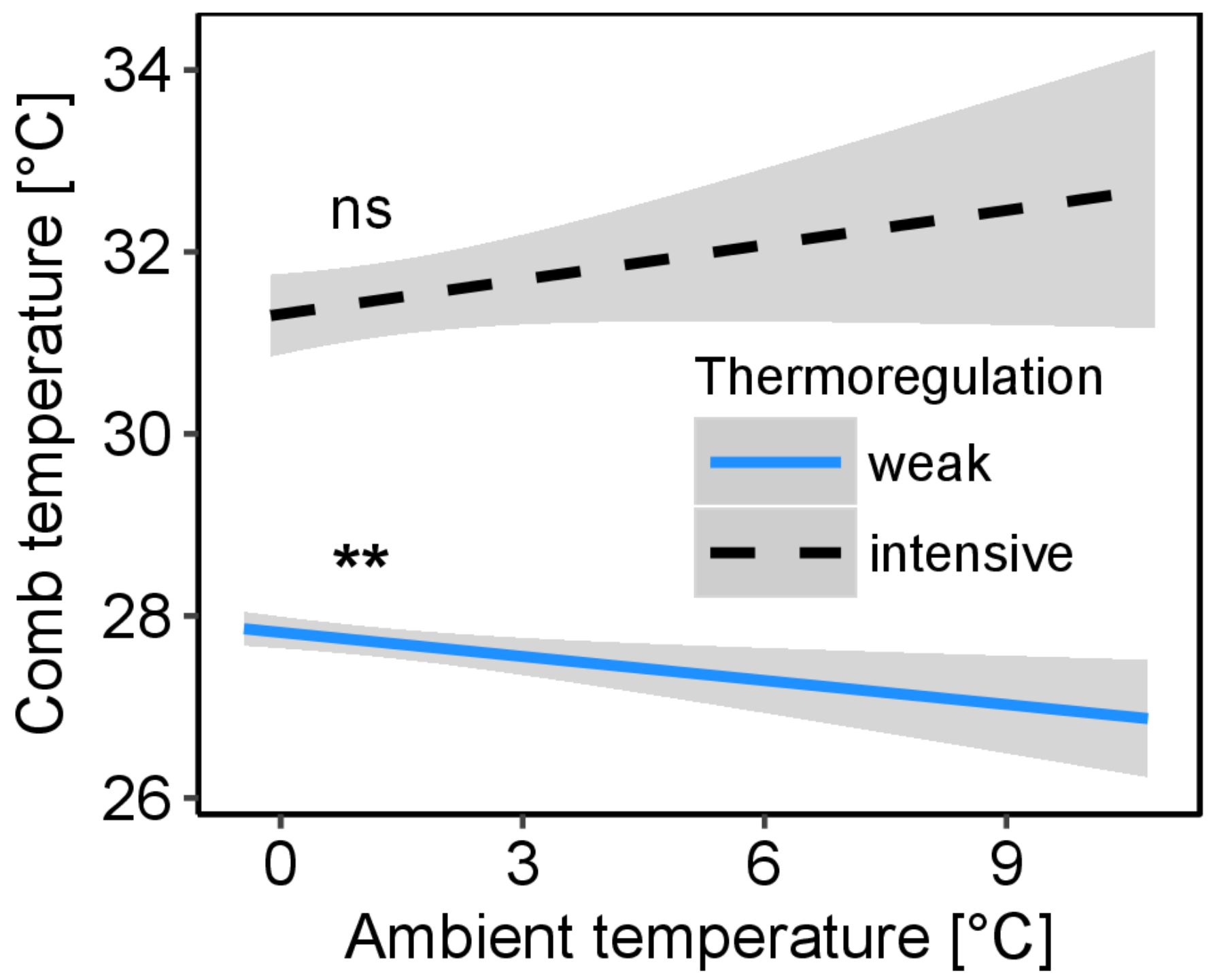




\section{Figure 4}

Depending on the light regime, ambient temperature conditions affected the proportion of days during which colonies were found to rear brood.

Cold: Colonies were kept at constant cold conditions for 30 days. Increase: a spell of warm ambient temperature for 15 days. Drop: after the phase of temperature increase, ambient temperature dropped again to cold conditions. Constant: constant short-day light regime with an $8 \mathrm{~h}$ photoperiod ( $n=189$ observation days from three colonies; blue); increasing: gradually increasing photoperiod starting at $8 \mathrm{~h}$ photoperiod ( $n=284$ observation days from four colonies; green); peaking: fast increase of photoperiod, starting at 8h photoperiod, peaking at $16 \mathrm{~h}$ photoperiod and followed by a fast decrease of photoperiod at the same point of time when temperature dropped again ( $n=279$ observation days from four colonies; orange). See Fig. 2 for more information. Generalized linear mixed-effects model. Tukey's test with Benjamini-Hochberg correction for post hoc analysis of diffrences between factors within light regimes. Letters: statistical groups. ns: $p>0.05$. Means \pm s.e.m..

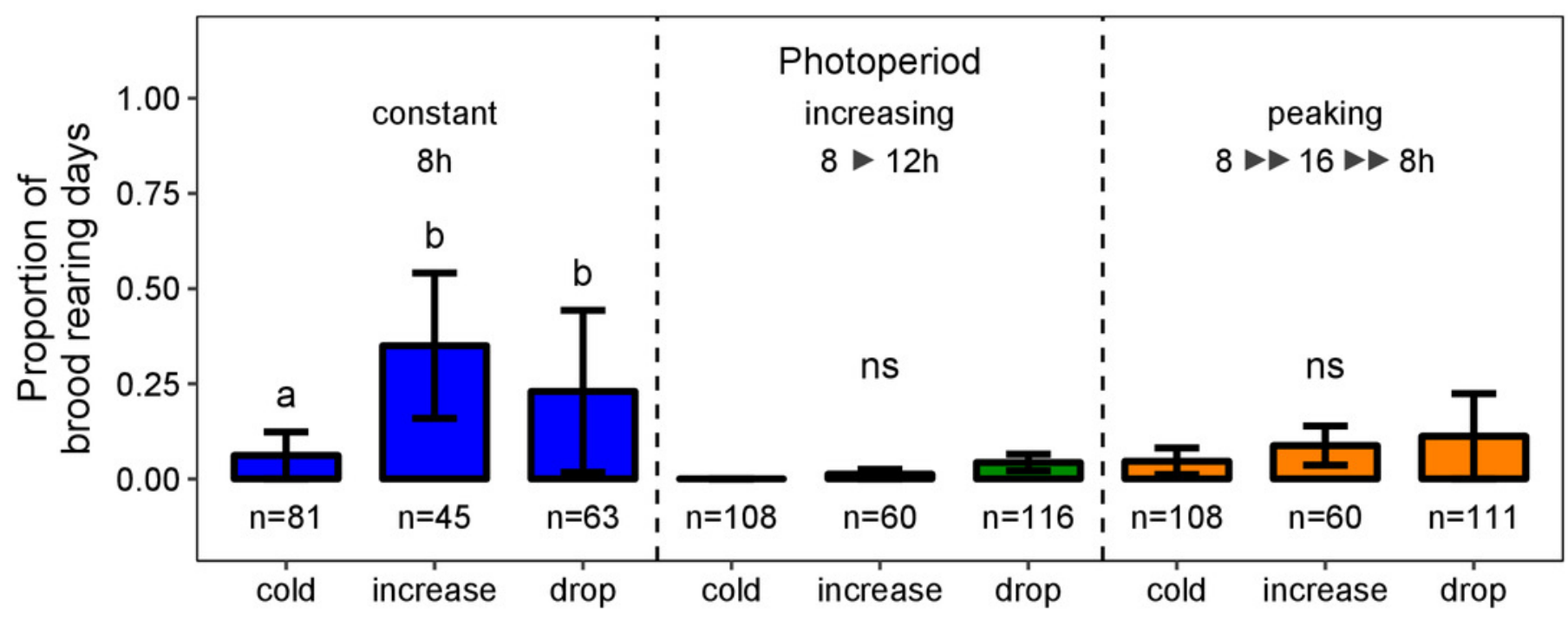

Ambient temperature conditions 
Figure 5

The proportion of brood rearing honey bee colonies was not significantly correlated with the duration of photoperiod under constant cold conditions.

$n=573$ observation days from eight colonies. Generalized linear mixed-effects model ns: $p$

$>0.05$. Grey area: $95 \%$ confidence interval.

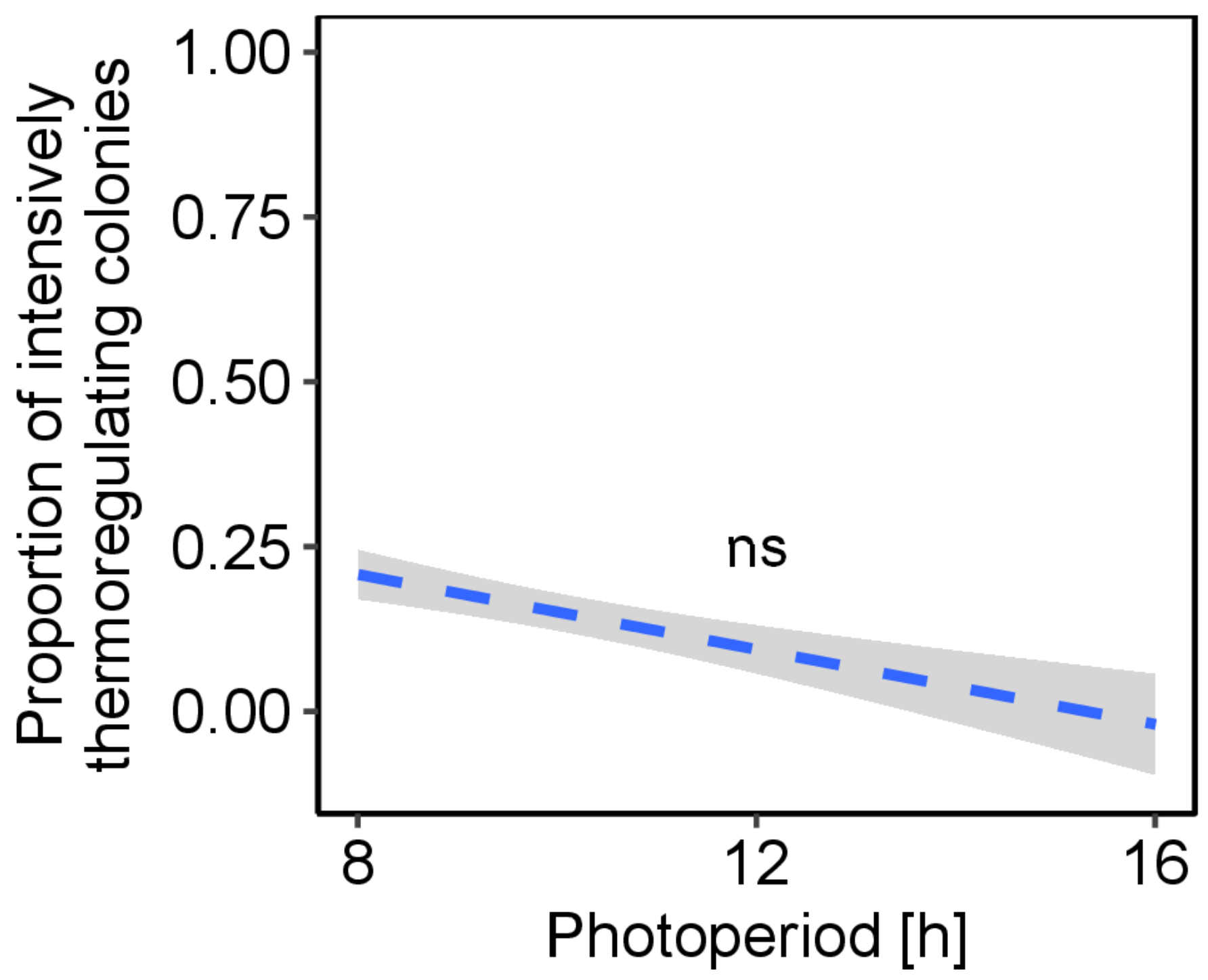


Figure 6

The proportion of days during which colonies were found to rear brood was not significantly affected by the direction of change of photoperiod under constant cold conditions.

Means \pm s.e.m.. Constant photoperiod: $n=225$ observation days from three colonies; increasing photoperiod: $n=279$ observation days from five colonies; decreasing photoperiod: $n=69$ observation days from three colonies. Linear mixed-effects model. $n s: p$ $>0.05$.

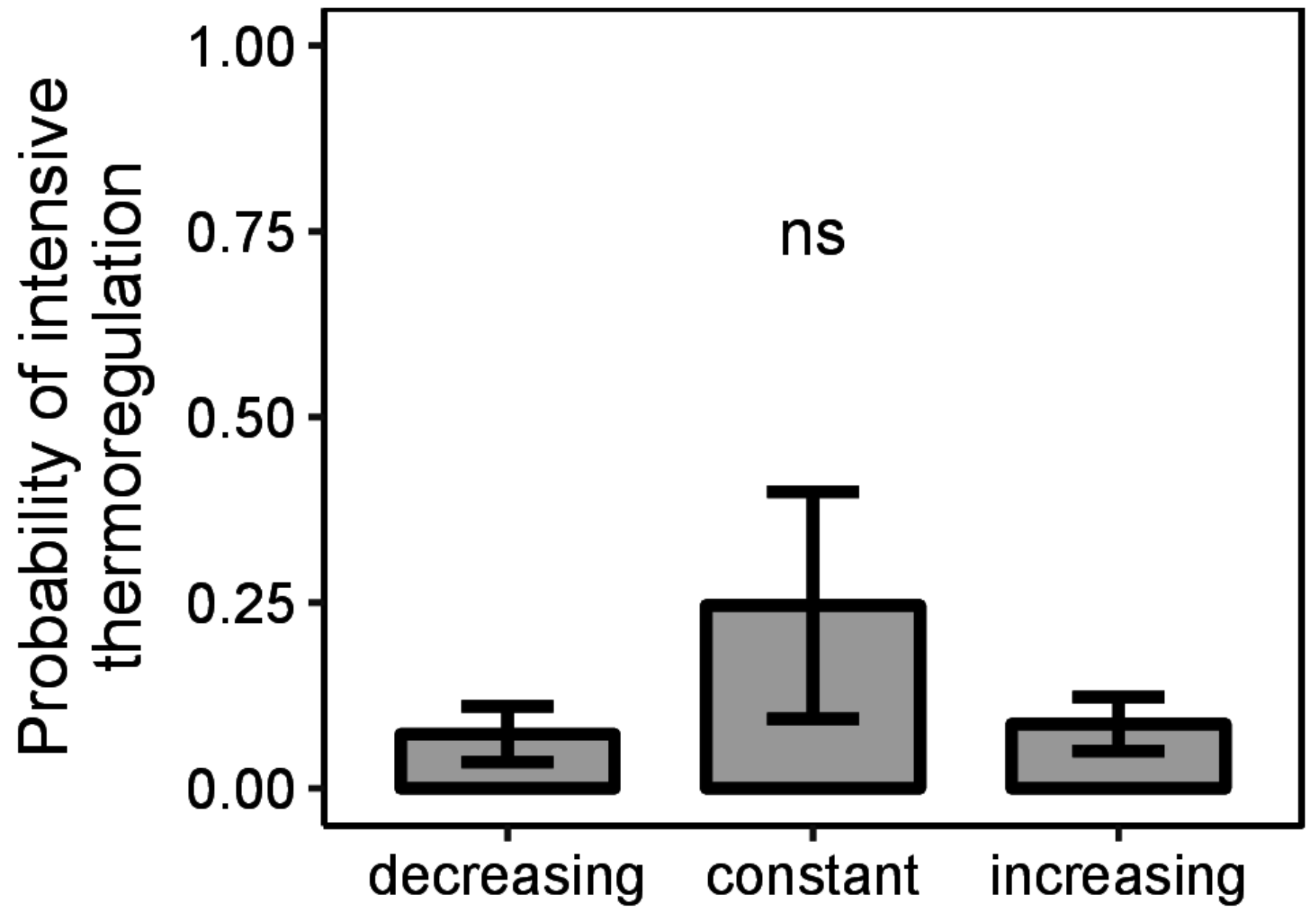

Photoperiod 
Figure 7

The proportion of brood rearing honey bee colonies increased significantly with the elapsed time.

Black: $n=1325$ observation days from 21 colonies regardless of temperature and light regime; blue: $n=225$ observation days from three colonies under constant cold and shortday conditions. Generalized linear mixed-effects model. Grey areas: 95\% confidence interval.

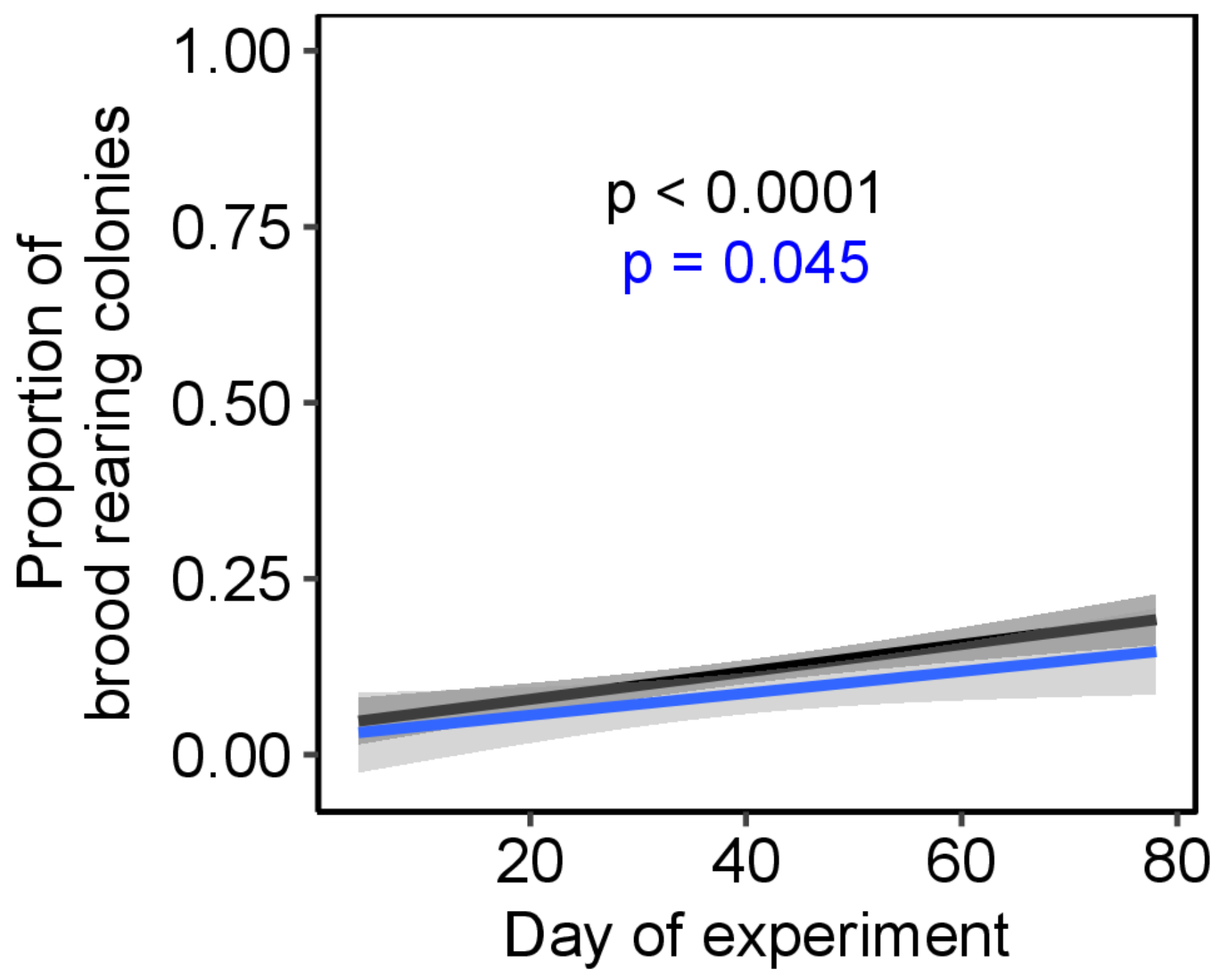

